\title{
Guess who's coming to dinner? Emerging foodborne zoonoses
}

\author{
David N Fisman MD MPH FRCPC ${ }^{1}$, Kevin Laupland MD MSc FRCPC ${ }^{2}$
}

Fo odborne infectious diseases sicken millions of Canadians every year, and are a major source of economic costs related to outbreak control, economic losses for food producers and vendors, and productivity costs among sickened individuals. Recent estimates suggest that more than 35 million cases of acute gastroenteritis occur in Canada annually, with an annual cost of more than $\$ 3$ billion (1); a majority of such illnesses are caused by contaminated food or water. Foodborne infections may also cause severe illness or even death, especially among individuals at the extremes of age and those with impaired immune functions (2). Common foodborne pathogens include commensal flora or pathogens found in animals consumed for food, those found in animalderived products (eg, Listeria species in cheese and deli meats) $(3,4)$ or those found in produce due to the contamination of fields with animal waste (5). Many foodborne illnesses are reasonably classified as zoonoses, and represent a good exemplar of the importance of the emerging 'one health' approach that links human and veterinary disease control efforts (6).

Recent challenges in the control of foodborne infectious diseases include centralization and industrialization of farming and food processing $(7,8)$, internationalization of food distribution (9) and the related globalization of cuisines (10). Similar to other infectious diseases, the apparent spectrum of foodborne pathogens has also changed as a result of the improved sensitivity of diagnostic methods, and some diseases that have historically been classed as vector-borne or waterborne are now being identified as transmitted through foods. As Canada emerges as a global hub for immigration, commerce and travel, it becomes increasingly important for Canadian clinicians to be aware of emerging infectious diseases in other geographical locales. In the present note, we describe the clinical features and evolving epidemiology of four emerging foodborne zoonoses.

\section{ANGIOSTRONGYLIASIS}

Angiostrongyliasis is most commonly a syndrome of eosinophilic meningitis due to infection with Angiostrongylus cantonensis (ie, the 'rat lungworm'). This parasite is a nematode with a life cycle that involves rodents (the parasite sheds its first-stage larva in their feces), and snails and slugs (larva matures into a third-stage larva that is infective to rodents and, incidentally, to humans). Humans are typically infected after consuming undercooked slugs or snails, infected crustaceans (crab or shrimp) or amphibians (frogs), or after consuming uncooked vegetables contaminated by slime from slugs or snails. Individuals may experience symptoms related to initial migration of larvae through the gastrointestinal mucosa, then via the liver through to the respiratory tract and, finally (approximately two weeks after initial infection), to the meninges. Constitutional symptoms, hyperesthesia and altered cutaneous sensations are also commonly reported. Worm migration may cause lesions in the brain or spinal parenchyma, and ocular migration can result in visual disturbances.

Although recovery of worms from cerebrospinal or ocular fluid represents the gold standard for diagnosis, this is achieved only in a minority of cases, and diagnosis is generally achieved through serological testing in individuals with eosinophilic meningitis, peripheral eosinophilia and a compatible clinical history (11). Most cases resolve with only supportive therapy (eg, analgesic agents for headache), but surgery may be required, particularly for ocular worms. The role of anthelmintic agents in most cases is uncertain; a placebo-controlled randomized trial (12) of albendazole showed significant reduction in the duration of headache with this drug; however, a randomized trial (13) comparing corticosteroids alone with albendazole plus corticosteroids found no difference in outcome between the two arms.

China, Taiwan and the Caribbean basin have historically represented the geographical distribution of angiostrongyliasis, and cases in these regions have usually occurred sporadically. However, since the 1990s, several outbreaks of angiostrongyliasis have been reported, one of which (in Beijing, China) was associated with more than 100 individuals hospitalized with eosinophilic meningitis (14). Intermediate snail hosts for angiostrongyliasis are widely distributed in China, and infected snails were identified in restaurants and markets during a recent national survey in that country (14). The potential for clusters of angiostrongyliasis in North America, as a result of travel to and migration from disease-endemic regions, was made clear by a 2005 outbreak of angiostrongyliasis in 12 American students returning from a spring break trip to Jamaica. An outbreak investigation linked infection to sharing of a large salad at a restaurant; infection was presumably related to the ingestion of lettuce that was contaminated by infected snails or slugs (15).

\section{CHAGAS DISEASE}

Chagas disease (American trypanosomiasis), caused by transmission of Trypanosoma cruzi, is endemic in South America, and is responsible for a high burden of disease in affected countries. Acute Chagas disease is most commonly a self-limited syndrome of fever, lymphadenopathy and myalgia, occasionally accompanied by such classic manifestations as the triad of conjunctivitis, periorbital edema and preauricular lymphadenopathy ipsilateral to the infecting insect bite (Romaña's sign). However, acute disease can be more severe and complicated by acute myocarditis or meningoencephalitis. Chronic Chagas disease is asymptomatic, but results in end-organ complications (cardiomyopathy,

\footnotetext{
${ }^{1}$ Division of Epidemiology, Dalla Lana School of Public Health, University of Toronto, Toronto, Ontario; ${ }^{2}$ Departments of Medicine, Critical Care Medicine, Pathology and Laboratory Medicine, Centre for Antimicrobial Resistance, University of Calgary, Calgary Laboratory Services, Calgary Health Region, Calgary, Alberta

Correspondence: Dr David N Fisman, Division of Epidemiology, Dalla Lana School of Public Health, 155 College Street, Room 678, Toronto, Ontario M5T 3M7. Telephone 416-978-6866, fax 416-978-8299, e-mail david.fisman@utoronto.ca
} 
megacolon and/or megaesophagus) that may be prevalent in up to three million persons in South America. The chronic complications of Chagas disease have been estimated to cause 14,000 deaths and 670,000 disability-adjusted life-years lost annually (16). Triatomine insects (ie, reduviid bugs, kissing bugs or assassin bugs) are the principal vector for Chagas disease, accounting for approximately $80 \%$ of transmissions, but transfusion of infected blood may account for $10 \%$ to $15 \%$ of new infections (17). Laboratory accidents, organ transplants and vertical transmission are also recognized mechanisms of transmission. While multinational initiatives to halt vector-borne transmission have led to significant reductions in infection incidence across South America, high levels of vector-borne transmission are still apparent in many areas - climate change could erase gains that have been made in disease control $(18,19)$.

While classically considered to be an insect vector-borne disease, foodborne Chagas disease has been recently recognized (20). Chagas may be acquired via consumption of fruits, sugar cane or their juices that are contaminated with triatomine insects, whether alive, dead or macerated as a result of juice production. Trypanosomal surface glycoproteins appear to facilitate binding to gastric mucin and epithelial cells. A glycoprotein (gp82) on the surface of metacyclic trypomastigotes promotes calciumdependent internalization of the parasite into host cells (21).

The first recognized outbreak of foodborne Chagas disease occurred in the affluent Brazilian state of Santa Catarina, which had no recent history of vector-borne Chagas disease at the time of the outbreak in 2005. Infection was demonstrated to be associated with consumption of contaminated sugar cane juice imported from a rural area with endemic Chagas disease (20). Subsequent small foodborne outbreaks have occurred in the less developed Amazonian rainforest states of Amazonas, Amapá and Pará, and also in the Santander district of Colombia. At the time of writing the present note (January 2009), a new outbreak associated with contaminated acai fruit had just been reported in Amazonas (22).

The two largest outbreaks to date have not been in Brazil, but in school settings in Venezuela. Both outbreaks were associated with the consumption of contaminated guava juice. The larger of the two outbreaks (in 2007) occurred in Caracas, a city without local vector-borne Chagas disease; the outbreak was identified after large numbers of children at a city school developed abdominal pain, fever and myalgia, and $T$ cruzi was identified in the blood of an affected student. Epidemiological investigation linked infection to the consumption of contaminated guava juice, which had been prepared in a rural area, in a kitchen heavily contaminated with infected triatomine insects, and was brought into the city for distribution. Of approximately 1000 exposed students, 103 were found to be infected; three-fourths were symptomatic, with common symptoms including fever (approximately 70\%), myalgias, chills, weakness, facial edema (approximately 10\%), abdominal pain (approximately 35\%) and diarrhea. Almost onethird of students had presumed myocarditis based on electrocardiographic abnormalities that included ST-segment abnormalities, atrioventricular block and supraventricular tachyarrhythmias. One child died of myocarditis. Additionally, one individual developed erythema nodosum in association with infection (23). In 2009, a similar outbreak, again associated with contaminated guava juice, occurred in students at a school in the Chichiriviche tourist region near Caracas, resulting in three deaths (24).
Treatment of the acute phase of Chagas disease with nifurtimox or benzimidazole is believed to improve the outcome; the sole fatality in the Caracas outbreaks was a child whose infection was untreated (23).

\section{NIPAH VIRUS}

Nipah virus is a newly discovered paramyxovirus, closely related to Hendra virus. It was first identified as the cause of a virulent outbreak of encephalitis in swine, Malaysian pig farmers and Singaporean abattoir workers in $1998(25,26)$. The virus is neurotropic, but also causes a diffuse vasculitis, with involvement of the lungs and the kidneys. Epidemiological investigations during the Malaysian outbreak suggested perturbation of local ecosystems as a result of expanded pig farming activity; the destruction of the rainforest contributed to the emergence of Nipah virus as a human pathogen (27), making this an exemplar of the importance of an 'ecosystem approach' to public health (28). Briefly, contact with infected pigs was identified as an important risk factor for encephalitis in farmers. Fruit bats in the area were identified as seropositive for Nipah virus, and the virus was isolated from the urine of infected bats. The mechanism of infection in pigs likely included consumption of partially eaten fruit contaminated by bats and released into pig enclosures, with a resulting large epizootic. Control measures were dramatic - more than one million pigs were culled $(26,29)$, and fruit trees were removed from the vicinity of pig farms. There have been no further swine-centred outbreaks of Nipah encephalitis in this region.

However, since that time, clusters of apparently sporadic human Nipah encephalitis have been identified in the Ganges delta region that spans the India-Bangladesh border, with secondary transmission occurring in approximately $7 \%$ of cases (30). Nipah encephalitis cases are seasonal, and occur predominantly between January and April (30). Case-control studies (31) identified tree climbing as an important risk factor for Nipah encephalitis, again suggesting that proximity to (and contamination by) tree-dwelling bats might play a role in infection. An outbreak of encephalitis affecting 12 individuals (11 of whom died) occurred in 2005 in the Tangail District of Bangladesh; outbreak investigation identified consumption of palm sap (OR 5.6, 95\% CI 1.7 to 7.9) as the only independent risk factor for encephalitis (32). Palm sap is an important food item in this region; it is consumed raw, boiled to make molasses or fermented to make a product known as 'tarin'. Qualitative information collected from the affected community suggested that contamination of palm sap pots by infected bats was likely - bat excreta were commonly found in sap, bats were known to drink from sap collection pots and were occasionally found (drowned) in these pots (32). Current interventions aimed at reducing the risk of infection via palm sap include provision of bamboo nets to sap harvesters because some individuals living in this area regard the sharing of syrup with bats as auspicious. These nets have been marketed based on the expectation that the protection of syrup stocks from contamination will result in increased profits for syrup harvesters and vendors (33).

\section{HEPATITIS E VIRUS}

Hepatitis E virus is a newly emerged calicivirus-like virus with four known genotypes. Infection causes a clinical spectrum of illness similar to that seen with hepatitis A virus, in that most infected individuals experience jaundice and transaminitis. Severe or fulminant infection can occur and has been 
prominently associated with pregnancy; adults younger than 50 years of age are most commonly affected (34). Most outbreaks have been identified in the Asian 'hepatitis E belt', and also in Africa, Oceania and Mexico. Outbreaks have been associated with fecal-oral transmission via contaminated drinking water or the mass movement of populations (eg, refugees), and usually involve viral strains of genotype 1 or 2 (34). By contrast, hepatitis $\mathrm{E}$ cases may occur sporadically in nontraveling individuals from high-income countries that have not been linked to hepatitis E outbreaks. Such cases are more commonly due to genotype 3 virus, similar to hepatitis $\mathrm{E}$ viruses identified in swine. A growing body of literature suggests that sporadic, 'nonclassical' hepatitis $\mathrm{E}$ is a foodborne zoonosis (35-38).

Hepatitis $E$ infection may occur in a number of nonhuman species, including bovines, swine, cats, dogs, rats and monkeys;

\section{REFERENCES}

1. Thomas MK, Majowicz SE, Pollari F, Sockett PN. Burden of acute gastrointestinal illness in Canada, 1999-2007: Interim summary of NSAGI activities. Can Commun Dis Rep 2008;34:8-15.

2. Gerba CP, Rose JB, Haas CN. Sensitive populations: Who is at the greatest risk? Int J Food Microbiol 1996;30:113-23.

3. Wilson K, Brownstein JS. Early detection of disease outbreaks using the Internet. CMAJ 2009;180:829-31.

4. MacDonald PD, Whitwam RE, Boggs JD, et al. Outbreak of listeriosis among Mexican immigrants as a result of consumption of illicitly produced Mexican-style cheese. Clin Infect Dis 2005;40:677-82.

5. Jay MT, Cooley M, Carychao D, et al. Escherichia coli O157:H7 in feral swine near spinach fields and cattle, central California coast. Emerg Infect Dis 2007;13:1908-11.

6. Kahn RE, Clouser DF, Richt JA. Emerging Infections: A Tribute to the One Medicine, One Health Concept. Zoonoses Public Health, 2009.

7. Hennessy TW, Hedberg CW, Slutsker L, et al. A national outbreak of Salmonella enteritidis infections from ice cream. The Investigation Team. N Engl J Med 1996;334:1281-6.

8. Salmonella Oranienburg infections associated with fruit salad served in health-care facilities - northeastern United States and Canada, 2006. MMWR Morb Mortal Wkly Rep 2007;56:1025-8.

9. Wheeler C, Vogt TM, Armstrong GL, et al. An outbreak of hepatitis A associated with green onions. N Engl J Med 2005;353:890-7.

10. Nawa Y, Hatz C, Blum J. Sushi delights and parasites: The risk of fishborne and foodborne parasitic zoonoses in Asia. Clin Infect Dis 2005;41:1297-303.

11. Wang QP, Lai DH, Zhu XQ, Chen XG, Lun ZR. Human angiostrongyliasis. Lancet Infect Dis 2008;8:621-30.

12. Jitpimolmard S, Sawanyawisuth K, Morakote N, et al. Albendazole therapy for eosinophilic meningitis caused by Angiostrongylus cantonensis. Parasitol Res 2007;100:1293-6.

13. Chotmongkol V, Kittimongkolma S, Niwattayakul K, Intapan PM, Thavornpitak Y. Comparison of prednisolone plus albendazole with prednisolone alone for treatment of patients with eosinophilic meningitis. Am J Trop Med Hyg 2009;81:443-5.

14. Lv S, Zhang Y, Liu HX, et al. Invasive snails and an emerging infectious disease: Results from the first national survey on Angiostrongylus cantonensis in China. PLoS Negl Trop Dis 2009;3:e368.

15. Slom TJ, Cortese MM, Gerber SI, et al. An outbreak of eosinophilic meningitis caused by Angiostrongylus cantonensis in travelers returning from the Caribbean. N Engl J Med 2002;346:668-75.

16. Tarleton RL, Reithinger R, Urbina JA, Kitron U, Gurtler RE. The challenges of Chagas Disease - grim outlook or glimmer of hope. PLoS Med 2007;4:e332.

17. Castro E. Chagas' disease: Lessons from routine donation testing. Transfus Med 2009;19:16-23.

18. Dias JC, Silveira AC, Schofield CJ. The impact of Chagas disease control in Latin America: A review. Mem Inst Oswaldo Cruz 2002;97:603-12.

19. Click Lambert R, Kolivras KN, Resler LM, Brewster CC, Paulson SL. The potential for emergence of Chagas disease in the United States. Geospat Health 2008;2:227-39.

20. Rodriguez-Morales AJ. Chagas disease: An emerging food-borne entity? J Infect Dev Ctries 2008;2:149-50. seroprevalence may be more than $10 \%$ in farmed pigs (39). In high-income countries, high levels of hepatitis E seropositivity have been identified in livestock farmers, veterinarians and butchers. Consumption of offal or wild boar has been linked to nonclassical, nontravel-related hepatitis E risk in Germany, the Netherlands and Japan, the latter country also having demonstrated a link with the consumption of undercooked venison (35-38). A study (40) in the United Kingdom identified an association between age and nontravel-related hepatitis E infection, which again may be related to the propensity of older individuals to eat organ meats that have fallen out of favour with younger diners. It remains to be seen whether the epidemiology of this disease is affected by the emerging 'snout to tail' culinary movement, which prizes consumption of offal and other meats that have lacked popularity among younger foodies (41).
21. Yoshida N. Molecular mechanisms of Trypanosoma cruzi infection by oral route. Mem Inst Oswaldo Cruz 2009;104(Suppl 1):101-7.

22. Trypanosomiasis-Brazil: (Amazonas) Food-borne. $<$ http://www.promedmail.org $>$ (Accessed on February 2, 2010).

23. Torres J. Orally-acquired Chagas' disease: A new urban threat in the Americas. <http://ww2.isid.org/Downloads/IMED2009_Presentations/ IMED2009_Torres.pdf $>$ (Accessed on January 5, 2010).

24. Trypanosomiasis, Foodborne-Venezuela: (Vargas), Guava Juice. $<$ http://www.promedmail.org $>$ (Accessed on January 15, 2010).

25. Yob JM, Field H, Rashdi AM, et al. Nipah virus infection in bats (order Chiroptera) in peninsular Malaysia. Emerg Infect Dis 2001;7:439-41.

26. Lam SK, Chua KB. Nipah virus encephalitis outbreak in Malaysia. Clin Infect Dis 2002;34:S48-51.

27. Chua KB, Chua BH, Wang CW. Anthropogenic deforestation, El Nino and the emergence of Nipah virus in Malaysia. Malays J Pathol 2002;24:15-21.

28. Daszak P, Cunningham AA, Hyatt AD. Emerging infectious diseases of wildlife - threats to biodiversity and human health. Science 2000;287:443-9.

29. Update: Outbreak of Nipah virus - Malaysia and Singapore, 1999. MMWR Morb Mortal Wkly Rep 1999;48:335-7.

30. Luby SP, Hossain MJ, Gurley ES, et al. Recurrent zoonotic transmission of Nipah virus into humans, Bangladesh, 2001-2007. Emerg Infect Dis 2009;15:1229-35.

31. Montgomery JM, Hossain MJ, Gurley E, et al. Risk factors for Nipah virus encephalitis in Bangladesh. Emerg Infect Dis 2008;14:1526-32.

32. Luby SP, Rahman M, Hossain MJ, et al. Foodborne transmission of Nipah virus, Bangladesh. Emerg Infect Dis 2006;12:1888-94.

33. Luby SP. Foodborne transmission of Nipah virus in Bangladesh. <http://ww2.isid.org/Downloads/IMED2009_Presentations/ IMED2009_Luby.pdf> (Accessed on January 2, 2010).

34. Krawczynski K, Aggarwal R, Kamili S. Hepatitis E. Infect Dis Clin North Am 2000;14:669-87.

35. Rutjes SA, Lodder WJ, Lodder-Verschoor F, et al. Sources of hepatitis E virus genotype 3 in The Netherlands. Emerg Infect Dis 2009; 15:381-7.

36. Wichmann O, Schimanski S, Koch J, et al. Phylogenetic and case-control study on hepatitis E virus infection in Germany. J Infect Dis 2008;198:1732-41.

37. Li TC, Chijiwa K, Sera N, et al. Hepatitis E virus transmission from wild boar meat. Emerg Infect Dis 2005;11:1958-60.

38. Tei S, Kitajima N, Ohara S, et al. Consumption of uncooked deer meat as a risk factor for hepatitis $\mathrm{E}$ virus infection: An age- and sex-matched case-control study. J Med Virol 2004;74:67-70.

39. Chandler JD, Riddell MA, Li F, Love RJ, Anderson DA. Serological evidence for swine hepatitis $\mathrm{E}$ virus infection in Australian pig herds. Vet Microbiol 1999;68:95-105.

40. Ijaz S, Arnold E, Banks M, et al. Non-travel-associated hepatitis E in England and Wales: Demographic, clinical, and molecular epidemiological characteristics. J Infect Dis 2005;192:1166-72.

41. Henderson F. The Whole Beast: Nose to Tail Eating New York: Ecco, 2004 


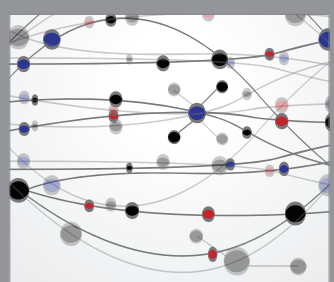

The Scientific World Journal
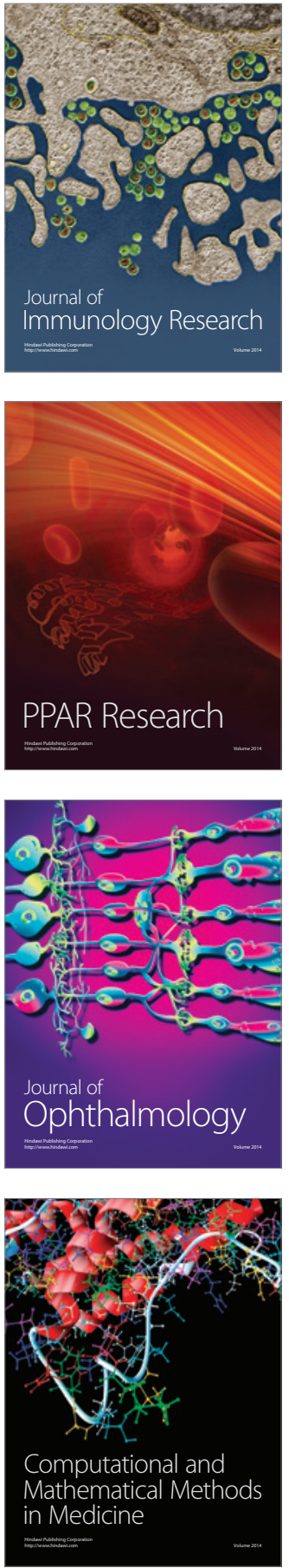

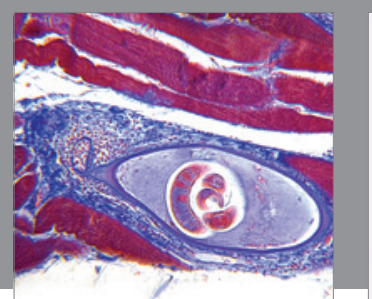

Gastroenterology Research and Practice

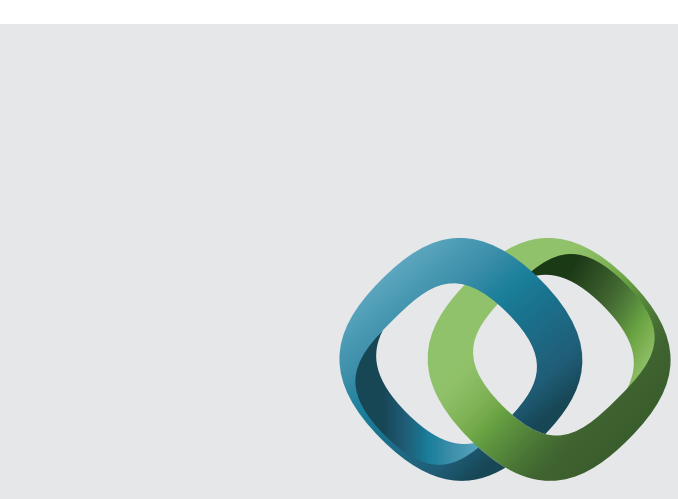

\section{Hindawi}

Submit your manuscripts at

http://www.hindawi.com
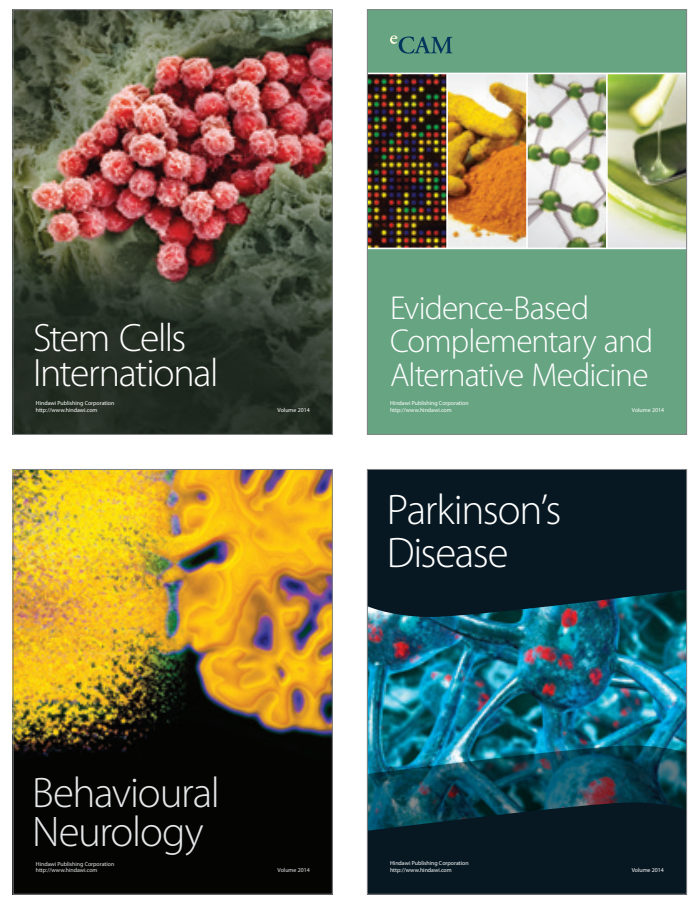
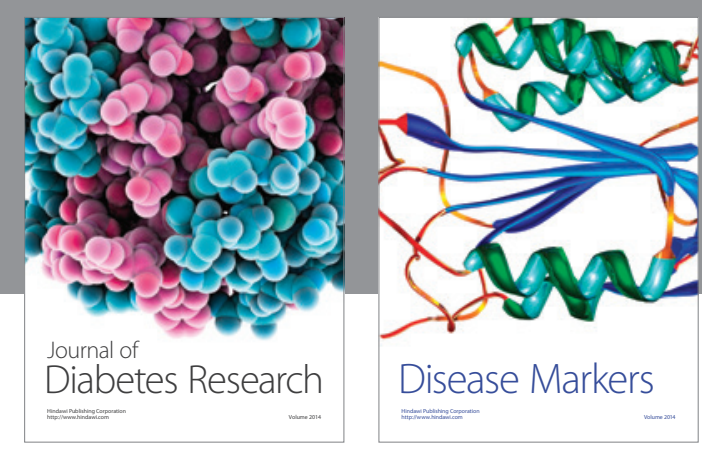

Disease Markers
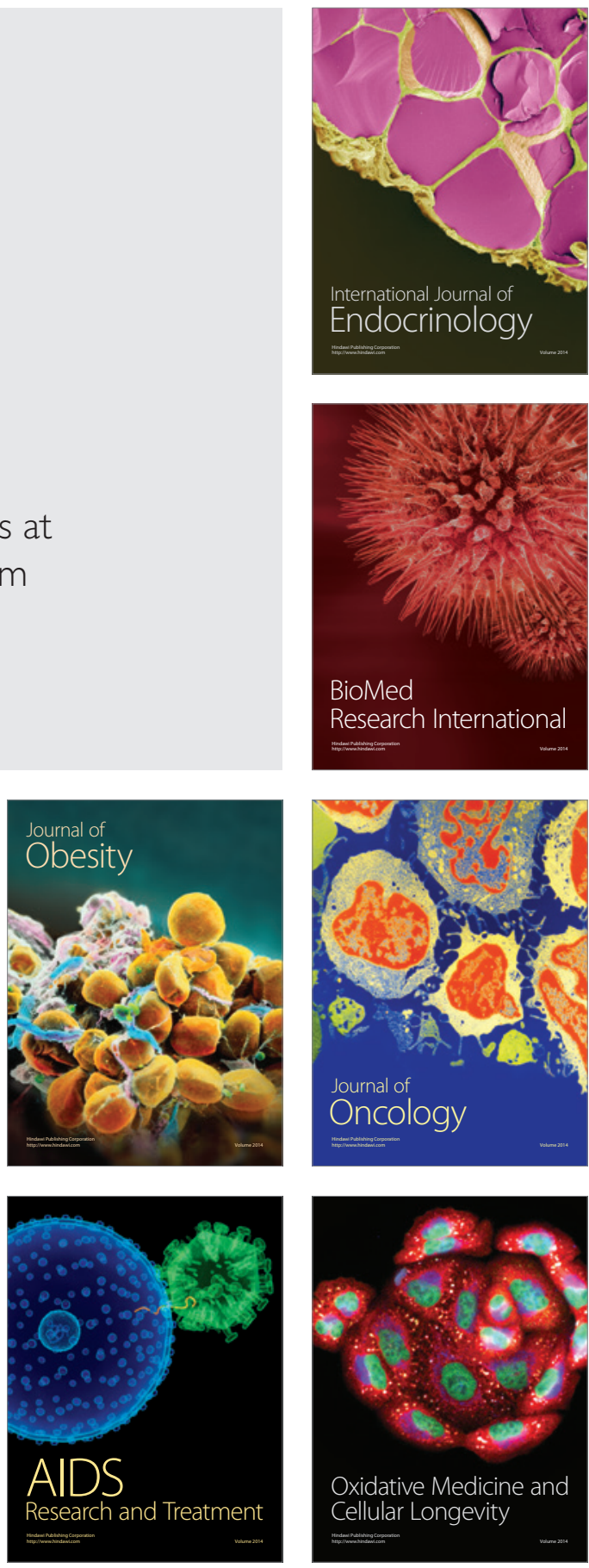